\title{
Behavioral sensitization: Characterization of enduring changes in rotational behavior produced by intermittent injections of amphetamine in male and female rats
}

\author{
Terry E. Robinson \\ Psychology Department and Neuroscience Laboratory Building, The University of Michigan, \\ 1103 E. Huron Street, Ann Arbor, MI 48104-1687, USA
}

\begin{abstract}
Factors influencing the behavioral sensitization ("reverse tolerance") produced by intermittent amphetamine (AMPH) injections were studied by quantifying rotational behavior in rats that had a unilateral 6-hydroxydopamine lesion of the substantia nigra. The results indicate that: (1) a single injection of a low dose of AMPH enhances rotational behavior induced by a second injection of AMPH for up to 12 weeks; (2) multiple, weekly injections of AMPH produce a progressive enhancement in rotational behavior, over-and-above that produced by a single injection; (3) female rats show more robust sensitization than males following single or multiple injections of AMPH; (4) this sex difference may be due to the suppression of sensitization by an androgen, because removal of testicular hormones potentiates sensitization; (5) the long-lasting sensitization of rotational behavior produced by infrequent injections of AMPH is not due to drug-environment conditioning effects, but perhaps to a persistent AMPH-induced change(s) in brain catecholamine systems; and (6) a simple change in DA receptors is probably not involved, because the sensitization produced by infrequent injections of AMPH does not influence the rotation produced by a subsequent injection of apomorphine. The results illustrate an intriguing example of neuroplasticity that may have clinical relevance.
\end{abstract}

Key words: Rotational behavior - Amphetamine Apomorphine - Sensitization - Sex differences - Gonadal hormones - Reverse tolerance - 6-Hydroxydopamine - Amphetamine psychosis - Conditioning - Dopamine Rat

\section{Introduction}

An unusual feature of psychomotor stimulant drugs is that some of their behavioral effects are progressively enhanced with repeated administration; a phenomenon known as sensitization or "reverse tolerance" (Klawans and Margolin 1975; Magos 1969; Segal and Mandell 1974; Wallach and Gerson 1971). In the majority of studies on behavioral sensitization, drugs such as amphetamine (AMPH) have been repeatedly administered and changes in the onset, vigor and/or duration of stereotyped behavior are determined (see Creese 1983 and Post 1981 for recent reviews). However, AMPH produces many different behaviors (e.g., Ungerstedt 1979), and some of these show sensitization, whereas others do not (e.g., Post 1981). It has recently been demonstrated, for example, that not even all the behavioral components of stereotypy show sensitization (Eichler et al. 1980; Rebec and Segal 1980).

One reason that not all AMPH-induced behaviors show sensitization may be because AMPH influences a number of functionally heterogeneous forebrain dopamine (DA) terminal fields (e.g., Iversen 1977; Ungerstedt 1979); and these presumably differ in their response to repeated AMPH (Eichler et al. 1980; Rebec and Segal 1980). Therefore, in attempting to relate changes in discrete neural structures to behavioral sensitization it will be important to know: (1) which neural locus is primarily responsible for the behavior under study, and (2) to what extent the characteristics of behavioral sensitization vary as a function of the behavior under study (i.e., the individual components of stereotypy, locomotion, wall climbing, rotation etc.).

We probably know more about the neural systems responsible for AMPH-induced rotational behavior than for any other DA-mediated behavior (Pycock 1980; Ungerstedt 1971; Ungerstedt and Arbuthnott 1970). For example, it is known that stereotypy and rotational behavior are mediated by different, albeit overlapping, neural systems (Iversen 1977; Ungerstedt 1979). It is therefore surprising that there have been no previous studies on the sensitization of rotational behavior produced by intermittent injections of AMPH in rats with unilateral 6-hydroxydopamine (6-OHDA) lesions of the nigrostriatal system (i.e., using the standard "Ungerstedt" model; Ungerstedt and Arbuthnott 1970). To my knowledge, there have only been four previous studies on the sensitization of AMPH-induced rotation; three with mice (Echols 1977, 1979; Jenner et al. 1978), and one with unlesioned rats (Robinson et al. 1982a). To extend our knowledge of behavioral sensitization, it seemed important to thoroughly characterize the effects of repeated AMPH administration on rotational behavior in rats with a unilateral 6-OHDA lesion. Therefore, studies are reported here on the influence of single vs multiple injections, inter-test interval, sex, gonadal hormones, and conditioning on the sensitization of AMPH-induced rotational behavior, and on the consequences of AMPH sensitization on rotation evoked by apomorphine.

\section{Materials and methods}

\section{Subjects}

The experiments were conducted with male and female Holtzman (Sprague-Dawley derived) rats (Holtzman Co., 
Madison, WI). All animals (200-300 $\mathrm{g}$ at time of surgery) were housed individually in wire-hanging cages with free access to food and water. The animal room was maintained on a reversed light : dark cycle $(14: 10 \mathrm{~h})$ with the lights going off at $06: 30 \mathrm{~h}$. All testing was conducted during the "night" portion of the rats' day/night cycle.

\section{Surgical procedures}

Thirty minutes after an injection of $15-25 \mathrm{mg} / \mathrm{kg}$ desipramine (Merrell-Dow Pharmaceuticals; Breese and Traylor 1971) each rat was anaesthetized with sodium pentobarbital, supplemented with methoxyflurane. A 30-gauge stainless steel cannula was lowered into the right rostral zona compacta of the substantia nigra using standard stereotaxic procedures (coordinates: posterior to bregma, $5.0 \mathrm{~mm}$; lateral to the saggital suture, $2.0 \mathrm{~mm}$; ventral to the skull surface, $7.3 \mathrm{~mm}$ - with bregma and lambda horizontal). The cannula was connected to a $10-\mu l$ syringe by PE10 tubing filled with a solution of 6-hydroxydopamine hydrobromide (6-OHDA) dissolved in $0.9 \%$ saline $(0.1 \mathrm{mg} / \mathrm{ml}$ ascorbic acid was added to retard oxidation). Each animal received 6-8 $\mu$ g-OHDA in a volume of $4 \mu \mathrm{l}$ over a 5-8-min infusion period. The cannula was left in place for 2 min following the infusion to minimize diffusion up the cannula track. The animals were allowed to recover from surgery for at least 4 weeks before any behavioral testing began.

\section{Procedures for recording rotational behavior}

Rotational behavior was measured in circular automated rotometers similar in principle to those described by Greenstein and Glick (1975). They had a diameter of $30 \mathrm{~cm}$, and flat bottom floors lightly covered with sawdust. The rotometers were interfaced with a microprocessor (AIM-65) that recorded every quarter turn $\left(90^{\circ}\right)$ made to the right or left during each 5-min interval. One complete rotation was defined as four consecutive $90^{\circ}$ turns in the same direction.

\section{Experimental design and protocol}

Experiment 1: Influence of inter-test interval in male and female rats. Following recovery from surgery, 68 female and 70 male rats were tested for AMPH-induced rotational behavior. Each rat was placed in a rotometer, and following a 15-min habituation period received an IP injection of $d$-amphetamine sulfate dissolved in $0.9 \%$ saline. Rotational behavior was then recorded for the next $2 \mathrm{~h}$. Half of the animals received a relatively low dose of AMPH $(1.0 \mathrm{mg} / \mathrm{kg}$ for males and $0.65 \mathrm{mg} / \mathrm{kg}$ for females) and half received a higher dose $(3.0 \mathrm{mg} / \mathrm{kg}$ for males and $2.6 \mathrm{mg} / \mathrm{kg}$ for females). Different doses of AMPH were used for males and females because sex differences in liver microsomal enzymes result in higher brain levels of AMPH in females given the same dose of AMPH as males (Becker et al. 1982; Conney 1967; Meyer and Lytle 1978). In previous studies we measured $\left[{ }^{3} \mathrm{H}\right]$ AMPH levels in whole brain and striatum of male and female rats after various doses of $\mathrm{AMPH}$, and at different points in time after injection (Becker et al. 1982). On the basis of these studies we are confident that the doses used here result in equivalent brain and striatal levels of AMPH in male and female rats.

Following this initial test session the animals were placed back into their home cage and left undisturbed until they were tested for rotational behavior a second time. This second test session was conducted either $24 \mathrm{~h}, 7$ days, 30 days, or 12 weeks ( 84 days) following the first session (all independent groups), using exactly the same procedures as in the 1st session (e.g., each rat received the same dose of $\mathrm{AMPH} / \mathrm{kg}$ in each test session).

Experiment 2: Single vs multiple injections. To compare the sensitization produced by single vs multiple injections of AMPH, the animals tested $24 \mathrm{~h}$ apart received three additional tests for rotational behavior, each separated by $24 \mathrm{~h}$; and the animals with 7 days between the first two tests also received three additional tests, but with 7 days between each test session. The animals were left undisturbed in their home cages between test sessions.

Experiment 3: Influence of gonadal hormones. To determine the influence of endogenous gonadal hormones on the development of behavioral sensitization, 17 female and 16 male rats received 6-OHDA lesions, as described above. Two weeks later they were gonadectomized under ether anaesthesia and allowed to recover for an additional 2 weeks. These animals were then tested weekly for AMPH-induced rotational behavior for 4 weeks. The same dose of AMPH $(3.0 \mathrm{mg} / \mathrm{kg})$ was used in gonadectomized males and females because Becker (unpublished studies; $\mathrm{cf}$ Becker et al. 1982) has found that there is no sex difference in the brain levels of AMPH produced by a systemic injection in gonadectomized rats.

Experiment 4: Role of conditioning. Two different experiments were conducted to examine the role of conditioning on the sensitization of rotational behavior by AMPH. Ovariectomized (OVX) female rats were used in both experiments because: (1) Expt. 3 and previous studies (Robinson et al. 1982a) established that OVX females show the same robust sensitization as intact females; and (2) it seemed likely that OVX females would show less inter-test variability than intact cycling females (Becker et al. 1982). The first "conditioning-control" experiment (Expt. 4a) was designed to determine if rotational behavior could be conditioned with relatively infrequent (weekly) injections of AMPH. All animals received 6-OHDA lesions, as described above. Two weeks later they were OVX, and then allowed an additional 2 weeks to recover before being randomly assigned to one of two groups: (1) Animals in the "conditioned" group $(n=14)$ were placed in the rotometers, allowed $15 \mathrm{~min}$ to habituate, and then received an IP injection of $3.0 \mathrm{mg} / \mathrm{kg}$ AMPH. Rotational behavior was recorded for $2 \mathrm{~h}$. This procedure was repeated weekly for a total of 4 weeks, but on the 4th week each animal received $0.9 \%$ saline instead of AMPH. (2) Animals in the control group $(n=16)$ were treated exactly the same as above except they received an injection of saline during each of the four weekly test sessions.

For the second conditioning-control experiment (Expt 4b) animals were surgically prepared, as described above, and then after 4 weeks of recovery were randomly assigned to one of three groups: (1) Animals in the "sensitization" group $(n=12)$ were tested for AMPH-induced $(3.0 \mathrm{mg} / \mathrm{kg})$ rotational behavior during four weekly test sessions, as described above. (2) The "saline control" animals $(n=16)$ were treated the same, except they received saline during the first 3 weekly test sessions, and $3.0 \mathrm{mg} / \mathrm{kg}$ AMPH 
during the fourth. (3) During the first 3 weekly test sessions "pseudoconditioned animals" $(n=15)$ were placed into the rotometers for $15 \mathrm{~min}$, before receiving an IP injection of saline. After $2 \mathrm{~h}$ they were removed from the rotometers, given an IP injection of $3.0 \mathrm{mg} / \mathrm{kg}$ AMPH, and placed in their home cages until the next test session. During the fourth test session these animals received $3.0 \mathrm{mg} / \mathrm{kg}$ AMPH in the rotometer, and rotational behavior was recorded. Thus, all the animals in this experiment received the same treatment during the fourth test session, but differed in terms of their prior history of drug-rotometer pairing.

Experiment 5: Cross-sensitization to apomorphine. This experiment was conducted to determine if the sensitization of rotational behavior to AMPH influences the rotation induced by a subsequent injection of a DA-receptor agonist, apomorphine (APO). OVX female rats were used for the reasons cited above. All animals received a unilateral 6-OHDA lesion of the substantia nigra, as described above. Two weeks later they were OVX and then allowed an additional 2 weeks to recover before being randomly assigned to one of two groups. Animals in the sensitization group received an IP injection of $3.0 \mathrm{mg} / \mathrm{kg}$ AMPH every 3-4 days for a total of five injections. Following each injection of AMPH, rotational behavior was recorded for $1 \mathrm{~h}$, as described above. Animals in the saline-control group were treated exactly the same, but received injections of saline instead of AMPH. Starting 1 week after the last $\mathrm{AMPH}$ or saline injection, all rats were tested for APO-induced rotation on four different occasions (3-4 days apart), with four different doses of APO $(30,60,240$, and $480 \mu \mathrm{g} / \mathrm{kg})$. APO was injected subcutaneously in the neck, and the order in which different doses were administered was counterbalanced so that approximately equal numbers of rats received each dose on each test day. Rotational behavior was recorded for $1 \mathrm{~h}$.

Neurochemical methods and procedures. At least 1 week following all behavioral testing the animals were killed by decapitation and the left and right striatum dissected on ice, weighed and placed in tubes containing $400 \mu l 0.05 \mathrm{~N}$ $\mathrm{HClO}_{4}$, with dihydroxybenzylamine $(2.5 \mathrm{ng} / 10 \mu \mathrm{l})$ added as an internal standard. The tissue was prepared for determination of DA concentrations using an alumina extraction procedure adapted from Felice et al. (1978), and described by Castañeda et al. (1984). The concentration of DA in the left and right striatum was determined using high performance liquid chromatography with electrochemical detection, as described previously (Castañeda et al. 1984).
Statistical tests. The data were analyzed with one or two-way analyses of variance, or $t$-tests, using software (Stats Plus and ANOVA II) obtained from Human Systems Dynamics (Northridge, CA).

\section{Results}

\section{Neurochemistry}

For Experiments 1-4 only data from rats that had at least an $80 \%$ depletion of right striatal DA (relative to the left) and turned ipsiversive were analyzed (mean DA depletion $\pm \mathrm{SD}=95.5 \pm 4.6 \%$ ). This was done to reduce variation in rotation rate due to differences in the extent of the 6-OHDA lesion, and to variation in the side of the lesion relative to the "dominant" hemisphere for rotational behavior (Robinson and Becker 1983). Unfortunately, the rats could not be prescreened to determine the dominant hemisphere prior to the 6-OHDA lesion in these experiments, as suggested by Robinson and Becker (1983), because obviously this would presensitize both experimental and control animals. In Expt. 5 only data from rats that had a greater than $95 \%$ depletion of right striatal DA, and turned contraversive when given APO were analyzed (mean DA depeletions 98.1-98.4\%). This was because although rats turn vigorously in response to AMPH after only a 50\% DA depletion, a much more extensive DA depletion is required before animals turn vigorously to low doses of APO (Hefti et al. 1980a, b).

\section{Experiment 1: Influence of inter-test interval on behavioral sensitization produced by a single exposure to AMPH in male and female rats}

Inter-test interval. To determine if there was an enhancement in rotational behavior between the first and second test session, difference scores were calculated by subtracting the number of rotations made during the first test session from those made during the second. If on the average a group made the same number of rotations during each test session their difference score should equal zero. A positive number indicates more rotations were made during the second test session than during the first. Single-sample $t$-tests were conducted to determine if the difference scores equaled zero (Table 1: all one-tailed tests because positive difference scores were predicted - Robinson et al. 1982a).

As predicted, all groups had positive difference scores (Table 1). Males treated with the higher dose of AMPH made significantly more rotations during the second test

Table 1. Difference in the number of rotations (mean \pm SEM) produced by amphetamine between two test sessions separated by $1,7,30$, or 84 days (see text)

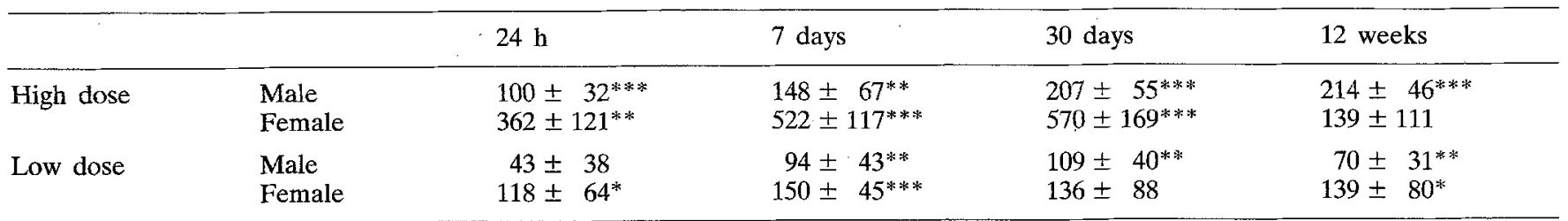

Differs from zero: ${ }^{*} t=1.7-1.8, P<0.053-0.06 ;{ }^{* *} t=2.2-2.7, P<0.033 ;{ }^{* * *} t=3.2-4.6, P<0.007$ 
session than during the first, regardless of whether the two sessions were separated by $1,7,30$, or 84 days. Males treated with the low dose of AMPH also made significantly more rotations during the second test than during the first, when the two test sessions were separated by 7,30 , or 84 days, but not 1 day $(t=1,1)$. However, there was no significant effect of inter-test interval on the size of the difference scores for either group (bigh dose, $F=1.2$, low dose, $F=0.6$ ).

In female rats a single injection of the higher dose of AMPH also produced a long-lasting enhancement in the rotational behavior produced by a second injection, when the two test sessions were separated by 1,7 , or 30 days (Table 1). However, females showed more variability in rotational behavior than males (see SEM values in Table 1), probably due to the estrous cycle (Becker et al. 1982). This variability, together with relatively low $n$ 's, may explain why there was not a significant difference between two test sessions separated by 84 days $(t=1.3, P=0.122$; Table 1$)$. Much of the variability in this group was due to one animal, which made 626 rotations during the first test and only 176 during the second. This was an extreme and unusually large decrease in rotational behavior, for which we have no explanation. If this one animal is omitted, the 84-day difference score is significantly different from zero $(t=2.3$, $P=0.028)$.

Pretreatment with the low dose of AMPH also enhanced rotational behavior in females when the two test sessions were separated by 1,7 , or 84 days, but not 30 days $(t=1.6, P=0.08$; Table 1). Again, the difference scores did not differ significantly as a function of inter-test interval (high dose, $F=2.5, P=0.08$; low dose $F=0.04$ ).

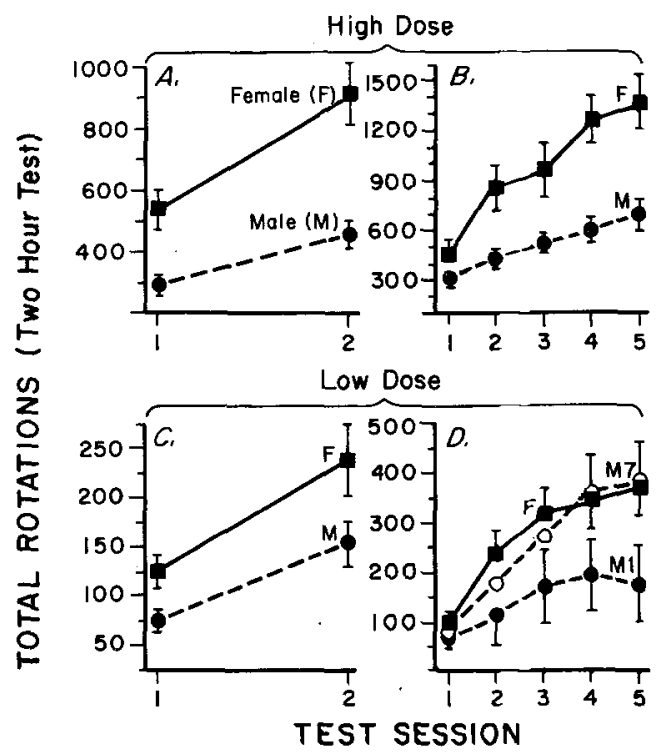

Fig. 1. The sensitization of rotational behavior produced by single or multiple injections of amphetamine in male or female rats. The ordinate shows the average ( \pm SEM) number of amphetamine-induced rotations made during a 2 -h test session (note different scales in $\mathbf{A}, \mathbf{B}, \mathbf{C}$, and $\mathbf{D}$ ). See the text for discussion of the time intervals between successive test sessions (abscissa), and the doses of amphetamine used. Abbreviations: $F$ females; $M$ males; $M 1$ males with 1 day between each test session; $M 7$ males with 7 days between each test session
Sex differences. Since analyses of variance revealed no significant effect of the inter-test intervals examined here, the groups were pooled to test for sex differences in the sensitization produced by a single injection of AMPH. Females $(n=36)$ treated with the higher dose of AMPH (Fig. 1A) made significantly more rotations than males $(n=35$; two-way analysis of variance - influence of sex, $F=16.9, P<0.001$ ). Both males and females made more rotations during the second test session than during the first (influence of session, $F=52.0, P<0.001$ ). However, a significant sex by session interaction indicates that females showed a more robust enhancement in rotational behavior between the two test sessions than did males (i.e., the lines in Fig. $1 \mathrm{~A}$ are not parallel, $F=7.7, P=0.007$ ).

Figure $1 \mathrm{C}$ illustrates that following treatment with the low dose of AMPH, females $(n=32)$ again made more rotations than males $(n=35 ; F=6.1, P=0.015)$. Both females and males made more rotations during the second test session than during the first $(F=25.8, P<0.001)$; however there was no sex difference in the magnitude of the enhancement in rotational behavior with this dose (interaction, $F=0.9)$.

\section{Experiment 2:}

Comparison of behavioral sensitization produced by single vs multiple injections of AMPH

in male and female rats

To compare the sensitization produced by single vs multiple injections of AMPH, male and female rats received either the low or higher dose of AMPH over five test sessions separated by either 1 day or 7 days (Figs. $1 B$ and 1D). There was no significant effect of inter-test interval following the higher dose of AMPH in either the males $(F=0.2)$ or females $(F=0.2)$, so the data were pooled in Fig. 1B. It is clear from Fig. 1B that there was a progressive enhancement in rotational behavior following multiple AMPH injections in both male $(n=16)$ and female $(n=18)$ rats, over-and-above that produced by a single

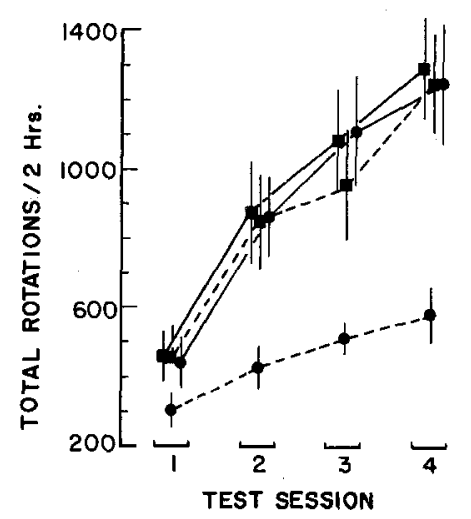

Fig. 2. The effects of gonadectomy on the sensitization of rotational behavior produced by four weekly injections of amphetamine. Note that overiectomized females (squares, solid line), intact females (squares, dotted line), and castrated males (circles, solid line) all showed an equivalent progressive enhancement in rotational behavior, which was significantly greater than of intact males (circles, dotted lines). Points represent the average ( \pm SEM) number of rotations in a 2 -h test session 
injection (two-way ANOVA, influence of test session $F=36.5, P<0.001)$. There was also a sex difference. Females showed a greater enhancement in rotational behavior over the five test sessions than did males, as indicated by a significant sex by session interaction $(F=6.8, \quad P<0.001$; main effect of sex, $F=10.5$, $P=0.003$ ).

Following the low dose of AMPH, there was no influence of inter-test interval in female rats ( 1 vs 7 days, $F=0.08$ ), and therefore the data were pooled (Fig. 1D). Figure 1D shows that again there was a progressive enhancement in rotational behavior over the five test sessions in female rats $(n=17)$, over-and-above that produced by a single injection $(F=15.1, P<0.001)$. Interestingly, male rats that received five weekly $(n=8)$ test sessions (M7) showed a greater enhancement in rotational behavior than did male rats that received the same low dose, but over five daily $(n=9)$ test sessions (M1; inter-test interval by session interaction, $F=2.7$, $P=0.037$, Fig. 1D). However, both of these latter groups (M1 and M7) did show a progressive enhancement in rotational behavior over the five test sessions $(F=3.8-10.8, P<0.01)$.

\section{Experiment 3: \\ Influence of endogenous gonadal hormones on the development of behavioral sensitization in male and female rats}

The sex difference in sensitization observed in experiments 1 and 2, and in previous studies (Robinson et al. 1982a), suggests that endogenous gonadal hormones may influence the development of behavioral sensitization. As a first step in exploring this idea gonadectomized male and female rats were studied. Figure 2 illustrates that castrated males (CAST; $n=16$ ) and ovariectomized females (OVX; $n=17$ ) showed an almost identical enhancement in rotational behavior over four weekly test sessions (influence of test session, $F=19.9, P<0.001$; influence of sex and interaction $F s<0.03$ ). For purposes of comparison, data for intact males and females shown in Fig. 1B are replotted on Fig. 2. It is clear that intact females, OVX females and CAST males all showed a greater enhancement in rotational behavior than did intact males (group by session interaction, $F=4.3, P<0.001$ ).

\section{Experiment 4:}

Role of conditioning in the sensitization

of rotational behavior produced

by infrequent injections of $A M P H$

In Expt. 4a we tried to condition rotational behavior by pairing an AMPH injection and a specific test environment (the rotometer) over three weekly test sessions. During the fourth test session all of the animals received saline in the rotometers to determine if conditioned rotational behavior would occur. Three weekly injections of AMPH did produce a progressive enhancement in rotational behavior (Fig. 3; $F=5.0, P=0.014$ ). The sensitized animals $(n=14)$ made an average of $941 \pm 144$ rotations during the third test session. If the sensitization produced by weekly injections of $\mathrm{AMPH}$ was primarily due to conditioning one would expect a subsequent injection of saline to produce fairly vigorous rotation. However, during the fourth test session a saline injection resulted in only $35 \pm 12$ rotations

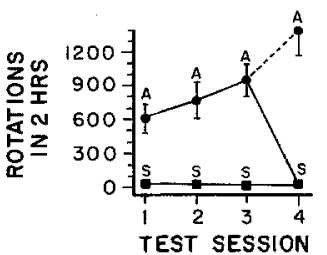

Fig. 3. The average ( \pm SEM) number of rotations produced during four weekly 2 -h test sessions. One group of animals received an injection of amphetamine $(A)$ during the first three test sessions, and saline $(S)$ during the fourth. Another group received four weekly injections of saline $(S)$. A third independent group received four weekly injections of amphetamine, and only the number of rotations made during their fourth session are shown (dashed line to fourth $A$ ). Where the standard errors are not shown it is because they are smaller than the symbol (see text)

in AMPH-pretreated rats, and $11 \pm 4$ rotations in saline-pretreated rats $(n=16 ; t=1.99, P=0.053)$. The dashed line and fourth "A" point in Fig. 3 show the number of rotations made by an independent group of animals that received a fourth injection of AMPH.

Three different treatment groups were compared in Expt. 4b: (1) A sensitized group $(n=12)$ pretreated with AMPH in the rotometers; (2) a saline control group $(n=16)$ pretreated with saline in the rotometers; and (3) a pseudoconditioned control group $(n=15)$ that previously received saline in the rotometers, and AMPH in their home cages. Figure 4 shows the number of rotations made over each 5-min interval of the fourth weekly test session, in which all groups received $3.0 \mathrm{mg} / \mathrm{kg} \mathrm{AMPH}$ in the rotometers. The number of rotations made by sensitized animals during their first test session is also shown for comparison. Group differences were determined with planned two-way analyses of variance.

As expected, four injections of AMPH at weekly intervals resulted in a robust, progressive enhancement in rotational behavior (Fig. 4). The more rapid onset of rotational behavior during the fourth test session, relative to the first, is reflected by a significant session by time interaction. During the fourth test session saline-pretreated control animals (Cont.) made the same number of rotations as did animals in the sensitization group the first time they received $\mathrm{AMPH}$, but significantly fewer rotations than sensitized animals the fourth time they received AMPH. Again, the more rapid onset of rotational behavior in sensitized animals $(S-4)$, relative to the saline-pretreated control group, is reflected by a significant group by time interaction. Therefore, simply being previously exposed to the rotometers does not significantly contribute to the large progressive enhancement in rotational behavior produced by the weekly administration of AMPH.

Figure 4 also shows that it is not necessary for AMPH administration to be paired with the specific environmental context of the rotometers to produce behavioral sensitization. Pseudoconditioned animals (PC.) made significantly more rotations than did either saline-pretreated control animals, or animals in the sensitization group the first time they received AMPH. Most importantly, pseudoconditioned animals did not differ from animals that had undergone three previous AMPH-rotometer pairings (PC. vs S-4, Fig. 4). 


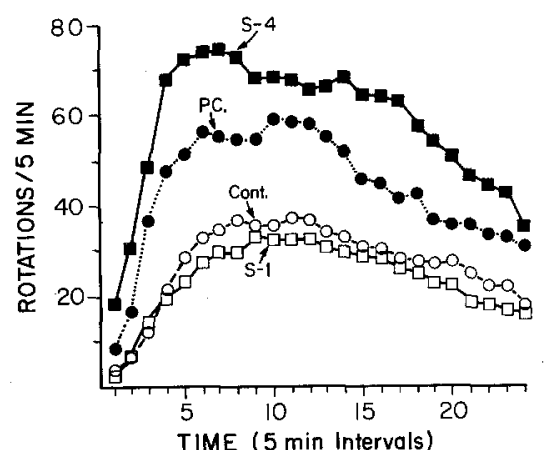

Fig. 4. Average number of rotations during each of 245 -min intervals following the administration of $3.0 \mathrm{mg} / \mathrm{kg}$ amphetamine. The groups differ in their previous history of drug-rotometer pairing. One group received four weekly injections of amphetamine in the rotometers, and the time course of rotational behavior is shown after the first $(S-1)$ and fourth $(S-4)$ exposure to the drug. Note the significant enhancement in rotational behavior between the first and fourth test ( $S-1$ vs $S-4,2$-way ANOVA, effect of session, $F=26.3, P<0.001$; session by time interaction, $F=2.2, P=0.001$ ). Saline-control rats (Cont.) received three weekly injections of saline in the rotometers, and then amphetamine during the fourth test session (Cont. vs $S-1, F=0.2$; Cont. vs $S-4$, effect of group, $F=9.3, P=0.005$, group by time interaction, $F=2.1, P=0.002$ ). During the first three weekly test sessions pseudoconditioned rats $(P C$.) received saline in the rotometers, and amphetamine $2 \mathrm{~h}$ later in their home cage. During the fourth test session they received amphetamine in the rotometers, and the time course of rotational behavior is shown. Groups with closed symbols differ from groups with open symbols, but not from each other ( $P C$. vs Cont., effect of group, $F=3.75$, $P=0.059$, but group by time interaction, $F=1.59, P=0.04 ; P C$. vs $S-1$, effect of group, $F=6.35, P=0.017$, interaction $F=1.82$, $P=0.011 ; P C$. vs $S-4$, effect of group, $F=1.94, P=0.17$, interaction $F=0.5$ )

\section{Experiment 5:}

The influence of $A M P H$ sensitization on the rotation produced by a subsequent injection of apomorphine

Figure 5 summarizes evidence showing that pretreatment with AMPH has no influence on the rotation induced by a subsequent injection of APO. Panel 5F shows that five injections of AMPH did indeed produce ipsiversive rotational behavior that was progressively enhanced with repeated injections (first test differs from fifth, $t=4.2$, $P<0.001$ ), and that saline injections resulted in no change in spontaneous rotational behavior over this period of time $(t=1.0, P=0.3$ ). Figure 5 (panels A-D) also shows the time course of the contraversive rotational behavior (negative numbers) induced by APO in AMPH and saline-pretreated rats. There were no differences between these groups when tested with $30,60,240$, or $480 \mu \mathrm{g} / \mathrm{kg}$ APO $(F$ 's $<0.7)$. Panel $5 E$ summarizes the cumulative contraversive rotations made during each 1 -h test session, at each dose, and it is clear that although the rate of rotation increases with increasing doses of APO $(F=29.1$, $P<0.001$, it does so identically in AMPH- and saline-pretreated rats $(F=0.9)$.

\section{Discussion}

The 12-week enhancement in rotational behavior following a single injection of AMPH reported here is a more
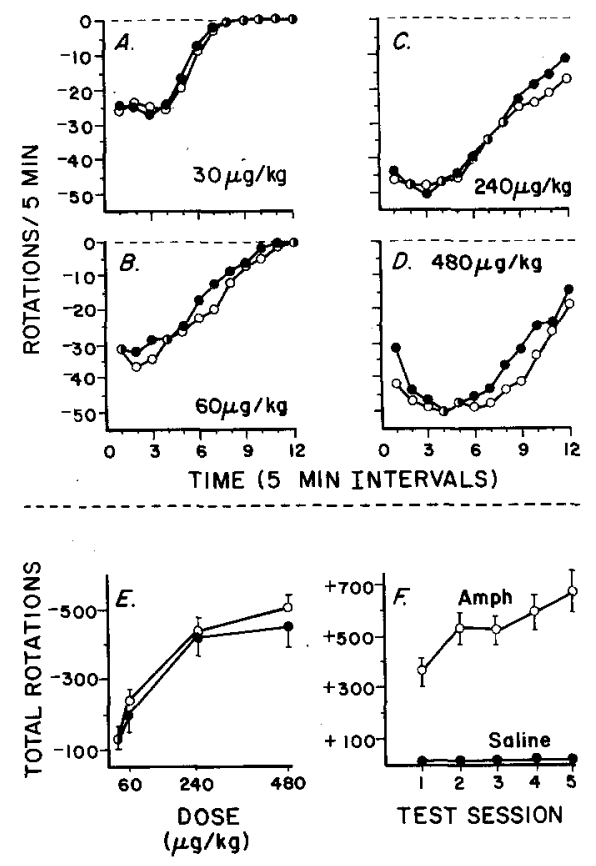

Fig. 5. The influence of $A M P H$ sensitization on the rotational behavior induced by a subsequent SC injection of APO. Positive numbers indicate ipsiversive rotations and negative numbers contraversive rotations. Panel $\mathbf{F}$ shows that intermittent injections of AMPH produced a progressive enhancement in ipsiversive rotational behavior $(P<0.001)$, whereas repeated saline injections had no effect on rotation (points represent the average number of rotations during each 1 -h test session \pm SEM). Panels A-D show the average number of contraversive rotations made by AMPH-(open circles) or saline-(closed circles) pretreated rats during each of 125 -min intervals following an injection of 30,60 , 240 , or $480 \mu \mathrm{g} / \mathrm{kg} \mathrm{APO}$, respectively. Note that the lower the number the greater the number of rotations. Panel $\mathbf{E}$ shows the total contraversive rotations made following each dose of APO over the entire 1-h test session. There was no effect of AMPH pretreatment on APO-induced rotation (see text)

enduring change in behavior than usually seen in the literature (see Table 3 in Post 1981). It is not known if this represents basic differences in the neurobehavioral substrate of stereotypy and rotational behavior, or whether previous researchers have simply not looked for such long-lasting changes in stereotypy. It is probably the latter, because it is known that a single injection of AMPH may have enduring consequences for a variety of behaviors. Magos (1969) originally reported that a single injection of AMPH facilitated stereotypy for up to $2-5$ weeks, and there have been a few subsequent reports that stereotypy (Browne and Segal 1977; Ellison and Morris 1981; Segal and Schuckit 1983), drinking (Antelman and Chiodo 1983), rotational behavior (Echols 1977; Robinson et al. 1982a) and tail pinch-induced behavior (Antelman et al. 1980) are enhanced for weeks after a single injection of AMPH.

It is clear that even moderate exposure to low doses of AMPH may have robust and long-lasting effects on behavior. In fact, our findings in male rats suggest that relatively infrequent multiple injections may be more efficiacious in producing sensitization than those given close together in time - supporting the analogy to kindling previously made (Post 1980; Post and Kopanda 1976; cf Antelman and Chiodo 1981). The results certainly suggest 
that the frequently administered (daily or twice daily) high doses of AMPH $(5-10 \mathrm{mg} / \mathrm{kg})$ used by many researchers to produce behavioral sensitization (see Table 3, Post 1981) are unnecessary, and perhaps in some cases are even counterproductive.

One reason that very aggressive drug regimens may be used is because it is thought that this more closely mimics the conditions that result in AMPH psychosis (Connell 1958; Griffith et al. 1972; Kramer et al. 1967). It is interesting that both the behavioral sensitization produced by multiple AMPH (or cocaine) injections (Post and Contel 1983; Segal and Janowsky 1978; Segal and Schuckit 1983) and the behavioral changes produced by continuous AMPH administration (Ellison and Eison 1983) have been presented as animal "models" of AMPH psychosis. In many respects these two modes of AMPH administration have opposite effects. For example, continuous AMPH administration destroys striatal DA terminals, resulting in DA depletion (Ellison et al. 1978; Ellison and Ratan 1982), whereas intermittent injections of AMPH do not deplete striatal DA (Kuczenski and Leith 1981), but facilitate striatal DA release (Robinson and Becker 1982; Robinson et al. 1982a).

Whether the continuous administration of AMPH provides a more realistic model of AMPH psychosis than intermittent injections is a matter for further debate and experimentation. However, in regards behavioral sensitization as an animal model of AMPH psychosis, it should be noted we found that intermittent injections of $\mathrm{AMPH}$ produced a progressive and long-lasting enhancement in rotational behavior, over-and-above that produced by a single injection. The progressive and enduring nature of the change is important for an animal model of AMPH psychosis because: (1) although AMPH psychosis may sometimes result from a single injection of AMPH (Segal and Janowsky 1978), the probability of inducing such behavioral and cognitive changes is thought to increase with repeated exposure to the drug (Ellinwood et al. 1973); and (2) former AMPH addicts are hypersensitive to AMPH even after 1-2 years of abstinence (Sato et al. 1983).

Regardless of the relative merit of intermittent vs continuous AMPH administration as an animal model of AMPH psychosis, the neuroplastic changes responsible for behavioral sensitization require elucidation. In searching for the neural basis of behavioral sensitization, it would seem wise to avoid too agressive drug treatment regimens. This is because the neurobehavioral changes produced by frequent high doses of $\mathrm{AMPH}$, or especially continuous AMPH administration, are probably unrelated to the behavioral sensitization produced by more infrequent exposure to low doses of AMPH (e.g., compare Kuczenski and Leith 1981; Robinson and Becker 1982; Robinson et al. 1982a with Ellison et al. 1978; Ricaurte et al. 1984; Steranka 1983). The experiments reported here establish a minimum set of criteria that must be met before any change identified in the nervous system can be seriously considered as being causally related to the sensitization of rotational behavior: (1) The change should be produced by a single, low dose of AMPH; (2) It should be greater following multiple injections spaced up to 1 week apart than following a single injection; (3) It should persist for very long periods of time (up to 12 weeks); and (4) sex and/or gonadal hormones should influence the magnitude of the change.
At present, there is little consensus as to what causes behavioral sensitization, and no hypothesis satisfies all of the above criteria. One hypothesis is that sensitization is largely due to drug-environment conditioning effects, because the repeated administration of psychomotor stimulants in a unique test environment can result in conditioned locomotion or stereotypy (Pickens and Dougherty 1971; Post et al. 1981; Schiff 1982; Tilson and Rech 1973). However, we found no evidence that the sensitization of rotational behavior produced by weekly injections of AMPH is due to conditioning, consistent with previous reports (Echols 1977; cf Browne and Segal 1977; Segal 1975). This is not to say that it is impossible to condition rotational behavior. Perhaps drug effects must be paired with the rotometer environment much more frequently than once a week for 5 weeks to condition this behavior.

There is also no evidence that behavioral sensitization is due to metabolic or other peripheral effects (Browne and Segal 1977; Kuczenski et al. 1982; Kuhn and Schanberg 1977). Therefore, the sensitization reported here may be due to an AMPH-induced change(s) in the functional activity of brain catecholamine neurons (Klawans and Margolin 1975; Martres et al. 1977; Segal and Mandell 1974). The nature of this putative change has not been well characterized. It is probably not a simple change in DA receptors, as indicated by the lack of an effect of AMPH sensitization on APO-induced rotation (Fig. 5), and the failure to find consistent changes in DA receptor binding (see Conway and Uretsky 1982 and Post 1981 for references). It may involve an enhancement in AMPH-stimulated DA release from striatal terminals (Robinson and Becker 1982; Robinson et al. 1982a; cf Kuczenski and Leith 1981).

\section{Sex differences and gonadal hormones}

We found strong and reliable sex differences in behavioral sensitization to AMPH (also see Robinson et al. 1982a). Females show more robust sensitization than males following single or multiple injections of $\mathrm{AMPH}$, and similar sex differences may occur following exposure to cocaine (S.D. Glick, personal communication; Post and Contel 1983). Although there has been one report of greater AMPH-induced sensitization in males than in females (Flemenbaum 1979), this was probably due to a ceiling effect in the females (cf Post and Contel 1983).

The cause of the sex difference in sensitization is not known. It is unlikely that it is due to sex differences in the metabolism of AMPH (Becker et al. 1982). Doses of AMPH were used to ensure that intact males and females had the same brain and striatal levels of AMPH (Becker et al. 1982), as did gonadectomized males and females (J.B. Becker, unpublished observations). Another possibility is that it is related to the well-documented sex difference in AMPH-induced rotational behavior (Becker et al. 1982; Brass and Glick 1981; Robinson et al. 1980). Females show more vigorous rotational behavior than males, and perhaps animals which show vigorous rotational behavior also are more prone to sensitization. However, in the present study there was no correlation between the number of rotations made during the first test session and the magnitude of the increase in rotational behavior between the two test sessions (as indicated by the difference scores, for males, 
$r=+0.204$; for females, $r=+0.042$; not significant). In contrast, there was a strong correlation between the number of rotations made during the second test session and the degree of sensitization (for males, $r=+0.67$; for females, $r=+0.75 ; P<0.01$ ). Thus, animals that turned the most during the second test session were animals that increased their rate of rotation the most; but they did not necessarily turn vigorously during their initial exposure to AMPH.

The effects of gonadectomy on sensitization (also see Robinson et al. 1982a) suggest that endogenous gonadal hormones influence the development of this form of neuroplasticity. Although removal of the ovaries in females had no effect on sensitization, castrated males showed greater sensitization than intact males, appearing very much like females. A working hypothesis is that the presence of a testicular hormone retards the development of sensitization. It should not be surprising that gonadal hormones might influence the behavioral sensitization produced by psychomotor stimulants, because gonadal hormones are known to normally modulate striatal DA activity (Becker and Ramirez 1981; Robinson et al. 1980, $1982 \mathrm{~b}$ ), to control patterns of neural connectivity during development (Arai 1981; Greenough et al. 1977; Raisman and Field 1973), to influence sprouting and regeneration (Milner and Loy 1982; Yu 1982), and to influence the development of receptor supersensitivity following the repeated administration of neuroleptics (Gnegy et al. 1983; Koller et al. 1980; cf Fujii and Ikeda 1982).

It is interesting to note that there are not only sex differences in this animal model of AMPH psychosis, but also in schizophrenia (Lewine 1981), and other psychopathologies in which brain catecholamine systems have been implicated (e.g., Weissman and Klerman 1977). In female schizophrenics the age of onset and of first hospitalization is later than in males, the symptoms in males and females differ considerably (typical vs atypical, respecitvely; Lewine 1981), and females have a more favorable clinical outcome than males (Watt et al. 1983). It has even been suggested that there may be sex-associated subtypes of schizophrenia (Lewine 1981). Although there has been considerable speculation as to the cause(s) of sex differences in psychopathology, there has been very little substantive research on the role that sex differences in brain organization might play. The experiments reported here suggest that further investigation of sex differences and gonadal hormone modulation in brain DA systems may be very fruitful in this regard.

Acknowledgements. This research was supported by Grant \#37277 from the NIMH and RCDA Award NS00844. I am indebted to Jill Moore for testing the animals, Jill Becker, Amy Angus, Dianne Camp, Eddie Castaneda, Jill Moore, and Peter Spencer for assistance with the assays, Marylin Hoy for typing the manuscript, Merrell-Dow Pharmaceuticals for the gift of the desipramine, and Jill Becker and Elliot S. Valenstein for their helpful comments on an earlier draft.

\section{References}

Antelman SM, Chiodo LA (1981) Dopamine autoreceptor subsensitivity: a mechanism common to the treatment of depression and the induction of amphetamine psychosis? Biol Psychiatry 16: 717-727
Antelman SM, Chiodo LA (1983) Amphetamine as a stressor. In: Creese I (ed) Stimulants: neurochemical, behavioral, and clinical perspectives. Raven Press, New York, p 269

Antelman SM, Eichler AJ, Black CA, Kocan D (1980) Interchangeability of stress and amphetamine in sensitization. Science 207:329-331

Arai Y (1981) Synaptic correlates of sexual differentiation. TINS Dec: $291-293$

Becker JB, Ramirez VD (1981) Sex differences in the amphetamine-stimulated release of catecholamines from rat striatal tissue in vitro. Brain Res 204:361-372

Becker JB, Robinson TE, Lorenz KA (1982) Sex differences and estrous cycle variations in amphetamine-elicited rotational behavior. Eur J Pharmacol 80:65-72

Brass CA, Glick SD (1981) Sex differences in drug-induced rotation in two strains of rats. Brain Res $223: 229-234$

Breese GR, Traylor TD (1971) Depletion of brain noradrenaline and dopamine by 6-hydroxydopamine. $\mathrm{Br} \mathrm{J}$ Pharmacol 42: 88-99

Browne RG, Segal DS (1977) Metabolic and experiential factors in the behavioral response to repeated amphetamine. Pharmacol Biochem Behav 6:545-552

Castañeda E, Robinson TE, Becker JB (1984) Involvement of nigrostriatal dopamine neurons in the contraversive rotational behavior evoked by electrical stimulation of the lateral hypothalamus. Brain Res (in press)

Connell PH (1958) Amphetamine psychosis. Chapman and Hill, London

Conney PH (1967) Pharmacological implications of microsomal enzyme induction. Pharmacol Rev 19:317-366

Conway PG, Uretsky NJ (1982) Role of striatal dopaminergic receptors in amphetamine-induced behavioral facilitation. J Pharmacol Exp Ther $221: 650-655$

Creese I (1983) Stimulants: Neurochemical, behavioral, and clinical perspectives. Raven Press, New York

Echols SD (1977) Circling of mice bearing unilateral striatal lesions: development of increased response to $d$-amphetamine. Life Sci 21:563-568

Echols SD (1979) Reverse tolerance to amphetamine of mice bearing unilateral striatal lesions: effect upon the circling response to apomorphine. Life Sci 24: 691-696

Eichler AJ, Antelman SM, Black CA (1980) Amphetamine stereotypy is not a homogeneous phenomenon: sniffing and licking show distinct profiles of sensitization and tolerance. Psychopharmacology 68:287-290

Ellinwood EH, Sudilovsky A, Nelson LM (1973) Evolving behavior in the clinical and experimental (model) psychosis. Am J Psychiatry 130: 1088-1092

Ellison G, Eison MS (1983) Continuous amphetamine intoxication: an animal model of the acute psychotic episode. Psychol Med 13: 751-761

Ellison G, Eison MS, Huberman HS, Daniel F (1978) Long-term changes in dopaminergic innervation of caudate nucleus after continuous amphetamine administration. Science $201: 276-278$

Ellison G, Morris W (1981) Opposed stages of continuous amphetamine administration: parallel alterations in motor stereotypies and in vivo spiroperidol accumulation. Eur J Pharmacol 74: 207-214

Ellison G, Ratan R (1982) The late stage following continuous amphetamine administration to rats is correlated with altered dopamine but not serotonin metabolism. Life Sci 31: 771-777

Felice LJ, Felice JD, Kissinger PT (1978) Determination of catecholamines in rat brain parts by reverse-phase ion-pair liquid chromatography. J Neurochem $31: 1461-1465$

Flemenbaum A (1979) Failure of apomorphine to induce dopamine receptor hypersensitivity. Psychopharmacology 62: 175-179

Fujii T, Ikeda H (1982) Sex difference in the development of hypersensitivity or tolerance to haloperidol in the rat. Jpn J Pharmacol 32: 247-254 
Gnegy ME, Bernabei A, Treisman G (1983) Chronic sulpiride treatment produces supersensitivity of striatal adenylate cyclase to dopamine in sexually immature or adult castrated rats. J Pharmacol Exp Ther 224:627-633

Greenough WT, Carter CS, Steerman C, DeVoogd TJ (1977) Sex differences in dendritic patterns in hamster preoptic area. Brain Res 126: 62-72

Greenstein S, Glick SD (1975) Improved automated apparatus for recording rotation (circling behavior) in rats and mice. Pharmacol Biochem Behav 3: 507-510

Griffith JD, Cavanaugh J, Held J, Oates JA (1972) Dextroamphetamine: evaluation of psychomimetic properties in man. Arch Gen Psychiatry 26:97-100

Hefti F, Melamed E, Wurtman RJ (1980a) Partial lesions of the dopaminergic nigrostriatal system in rat brain: biochemical characterization. Brain Res 195: 123-137

Hefti F, Melamed E, Sahakian BJ, Wurtman RJ (1980b) Circling behavior in rats with partial, unilateral nigro-striatal lesions: effect of amphetamine, apomorphine, and DOPA. Pharmacol Biochem Behav 12: 185-188

Iversen SD (1977) Brain dopamine systems and behavior. In: Iversen LL, Iversen SD, Snyder SH (eds) Handbook of psychopharmacology. vol. 8, Plenum, New York, p 333

Jenner P, Pycock C, Marsden CD (1978) The effect of chronic administration and withdrawal of amphetamine on cerebral dopamine receptor sensitivity. Psychopharmacology 58: $131-136$

Klawans HL, Margolin DI (1975) Amphetamine-induced dopaminergic hypersensitivity in guinea pigs. Arch Gen Psychiatry 32: $725-732$

Koller WC, Weiner WJ, Klawans HL, Nausieda PA (1980) Influence of female sex hormones on neurolepticinduced behavioral supersensitivity. Neuropharmacology 19: $387-391$

Kramer JC, Fischman VS, Littlefield DC (1967) Amphetamine abuse. JAMA 201: 305-309

Kuczenski R, Leith NJ (1981) Chronic amphetamine: is dopamine a link in or a mediator of the development of tolerance and reverse tolerance? Pharmacol Biochem Behav 15: 405-413

Kuczenski R, Segal DS, Weinberger SB, Browne RG (1982) Evidence that a behavioral augmentation following repeated amphetamine administration does not involve peripheral mechanisms. Pharmacol Biochem Behav 17:547-553

Kuhn CM, Schanberg SM (1977) Distribution and metabolism of amphetamine in tolerant animals. In: Ellinwood EH, Kilbey MM (eds) Cocaine and other stimulants. Plenum, New York, $\mathrm{p} 161$

Lewine RRJ (1981) Sex differences in schizophrenia: timing or subtypes? Psychol Bull 90: 432-444

Magos L (1969) Persistence of the effect of amphetamine on stereotyped activity in rats. Eur J Pharmacol 6: 200-201

Martres PMP, Costentin J, Baudry M, Marcais H, Protais P, Schwartz JC (1977) Long-term changes in the sensitivity of preand post-synaptic dopamine receptors in mouse striatum evidenced by behavioral and biochemical studies. Brain Res 136: 319-337

Meyer Jr. EM, Lytle LD (1978) Sex related differences in the physiological disposition of amphetamine and its metabolites in the rat. Proc West Pharmacol Soc 21: 13-316

Milner TA, Loy R (1982) Hormonal regulation of axonal sprouting in the hippocampus. Brain Res 243: 180-185

Pickens R, Dougherty JA (1971) Conditioning of the activity effects of drugs. In: Thompson TI, Pickens R (eds) Stimulus properties of drugs. Appleton-Century-Crofts, New York, p 39

Post RM (1980) Intermittent versus continuous stimulation: effect of time interval on the development of sensitization or tolerance. Life Sci 26: $1275-1282$

Post RM (1981) Central stimulants: clinical and experimental evidence on tolerance and sensitization. In: Israel Y, Glaser FB, Kalant H, Pophano RE, Schmidt W, Smart RG (eds)
Research advances in alcohol and drug problems. Vol. 6, Plenum Press, New York, p 1

Post RM, Contel NR (1983) Human and animal studies of cocaine: implications for development of behavioral pathology. In: Creese I (ed) Stimulants: Neurochemical, behavioral, and clinical perspectives. Raven Press, New York, p 169

Post RM, Kopanda RT (1976) Cocaine, kindling, and psychosis. Am J Psychiatry 133: 627-634

Post RM, Lockfeld A, Squillace KM, Contal NR (1981) Drug-environment interaction: context dependency of cocaine-induced behavioral sensitization. Life Sci $28: 755-760$

Pycock CJ (1980) Turning behavior in animals. Neuroscience $5: 461-514$

Raisman G, Field PM (1973) Sexual dimorphism in the neuropil of the preoptic area of the rat and its dependence on neonatal androgen. Brain Res 54:1-29

Rebec GV, Segal DS (1980) Apparent tolerance to some aspects of amphetamine stereotypy with long-term treatment. Pharmacol Biochem Behav 13: 793-797

Ricaurte GA, Guillery RS, Seiden LS, Schuster CR (1984) Nerve terminal degeneration after a single injection of D-amphetamine in iprindole treated rats: relation to selective long-lasting dopamine depletion. Brain Res 291:378-382

Robinson TE, Becker JB (1983) The rotational behavior model: asymmetry in the effects of unilateral 6-OHDA lesions of the substantia nigra in rats. Brain Res 264: 127-131

Robinson TE, Becker JB (1982) Behavioral sensitization is accompanied by an enhancement in amphetamine-stimulated dopamine release from striatal tissue in vitro. Eur J Pharmacol 85:253-254

Robinson TE, Becker JB, Presty SK (1982a) Long-term facilitation of amphetamine-induced rotational behavior and striatal dopamine release produced by a single exposure to amphetamine: sex differences. Brain Res 253:231-241

Robinson TE, Becker JB, Ramirez VD (1980) Sex differences in amphetamine-elicited rotational behavior and the lateralization of striatal dopamine in rats. Brain Res Bull 5:539-545

Robinson TE, Camp DM, Jacknow DS, Becker JB (1982b) Sex differences and estrous cycle dependent variation in rotational behavior elicited by electrical stimulation of the mesostriatal dopamine system. Behav Brain Res 6: 273-287

Sato M, Chen C-C, Akiyama K, Otsuki S (1983) Acute exacerbation of paranoid psychotic state after long-term abstinence in patients with previous methamphetamine psychosis. Biol Psychiatry 18: 429-440

Schiff SR (1982) Conditioned dopaminergic activity. Biol Psychiatry $17: 135-154$

Segal DS (1975) Behavioral and neurochemical correlates of repeated $d$-amphetamine administration. In: Mandell AJ (ed) Neurobiological mechanisms of adaptation and behavior. Raven Press, New York, p 247

Segal DS, Janowsky. DS (1978) Psychostimulant-induced behavioral effects: possible models of schizophrenia. In: Lipton MA, DiMascio A, Killam KF (eds) Psychopharmacology: A generation of progress. Raven Press, New York, p 1113

Segal DS, Mandell AJ (1974) Long-term administration of $d$-amphetamine: progressive augmentation of motor activity and stereotypy. Pharmacol Biochem Behav 2:249-255

Segal DS, Schuckit MA (1983) Animal models of stimulant-induced psychosis. In: Creese I (ed) Stimulants: Neurochemical, behavioral, and clinical perspectives. Raven Press, New York, p 131

Steranka LR (1983) Long-term effects of a priming dose and short-term infusion of amphetamine on striatal dopamine neurons in rats. Eur J Pharmacol 96:159-163

Tilson HA, Rech RH (1973) Conditioned drug effects and absence of tolerance to $d$-amphetamine induced motor activity. Pharmacol Biochem Behav 1:149-153 
Ungerstedt U (1979) Central dopamine mechanisms and unconditioned behavior. In: Horn AS, Korf J, Westerink BH (eds) The neurobiology of dopamine. Academic Press, London, p 577

Ungerstedt U (1971) Striatal dopamine release after amphetamine or nerve degeneration revealed by rotational behavior. Acta Physiol Scand (Suppl 367) 82:49-68

Ungerstedt U, Arbuthnott GW (1970) Quantitative recording of rotational behavior in rats after 6-hydroxydopamine lesions of the nigrostriatal dopamine system. Brain Res 24:485-493

Wallach MB, Gershon S (1971) Sensitization to amphetamines. Psychopharmacol Bull 7:30-31
Watt DC, Katz K, Shepherd M (1983) The natural history of schizophrenia: a 5-year prospective follow-up of a representative sample of schizophrenics by means of a standardized clinical and social assessment. Psychol Med 13:663-670

Weissman MM, Klerman GL (1977) Sex differences and the epidemiology of depression. Arch Gen Psychiatry 34: $98-111$

Yu WA (1982) Sex difference in the regeneration of the hypoglossal nerve in rats. Brain Res 238:404-406

Received March 26, 1984; Final version August 15, 1984 